\title{
Meeting the sexual health needs of men who have sex with men in Senegal
}

Cheikh Ibrahima Niang

Moustapha Diagne

Youssoupha Niang

Amadou Moreau

Dominique Gomis

See next page for additional authors

Follow this and additional works at: https://knowledgecommons.popcouncil.org/departments_sbsr-hiv

Part of the Demography, Population, and Ecology Commons, Gender and Sexuality Commons, Health Policy Commons, Immune System Diseases Commons, International Public Health Commons, Medicine and Health Commons, Public Health Education and Promotion Commons, and the Virus Diseases Commons

How does access to this work benefit you? Let us know!

\section{Recommended Citation}

Niang, Cheikh Ibrahima, Moustapha Diagne, Youssoupha Niang, Amadou Moreau, Dominique Gomis, Maye Diouf, Karim Seck, Abdoulaye Sidibe Wade, Placide Tapsoba, and Christopher Castle. 2002. "Meeting the sexual health needs of men who have sex with men in Senegal," Horizons Final Report. Washington, DC: Population Council. 


\section{Authors}

Cheikh Ibrahima Niang, Moustapha Diagne, Youssoupha Niang, Amadou Moreau, Dominique Gomis, Maye Diouf, Karim Seck, Abdoulaye Sidibe Wade, Placide Tapsoba, and Christopher Castle 


\section{Horizons}

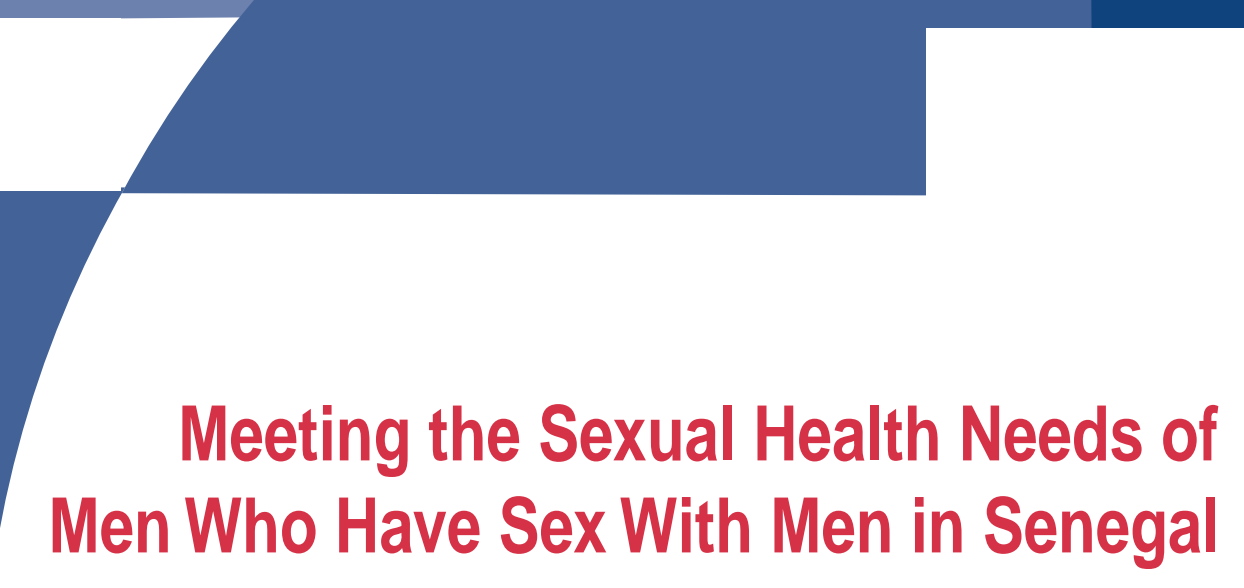

Institute of Enironmental Sciences, Cheikh Anta Diop University Senegal National AIDS Control Council (CNLS) Horizons Program 


\section{Meeting the Sexual Health Needs of Men Who Have Sex With Men in Senegal}

Cheikh Ibrahima Niang, Moustapha Diagne, Youssoupha Niang, Amadou Mody Moreau, Dominique Gomis, and Mayé Diouf

Institute of Environmental Sciences, Cheikh Anta Diop University

Karim Seck and Abdoulaye Sidibé Wade

Senegal National AIDS Control Council (CNLS)

Placide Tapsoba

Horizons/Population Council

Chris Castle

Horizons/International HIV/AIDS Alliance 


\section{Acknowledgments}

The researchers would like to acknowledge the following organizations that helped with the study: Conseil National de Lutte contre le Sida (National AIDS Control Council), Institut des Sciences de l'Environnement (Environmental Science Institute), African Consultant International, Organisation Panafricaine de Lutte contre le Sida/Centre de Traitement Ambulatoire (PanAfrican Organization for AIDS Control/ Center for Outpatient Treatment), Family Health International/Impact, and

USAID/Dakar.

Thanks to those who provided technical and editorial comments on this report, including Margaret Dadian and Ellen Weiss of the Horizons Program, and to Sherry Hutchinson for layout.

In addition, we would like to thank all of the individuals who participated in this research.

USAID This study was supported by the Horizons Program, which is implemented by the Population Council in collaboration with the International Center for Research on Women, International HIV/AIDS Alliance, Program for Appropriate Technology in Health, Tulane University, Family Health International, and Johns Hopkins University. Horizons is funded by the U.S. Agency for International Development, under the terms of HRN-A-00-97-00012-00. The opinions expressed herein are those of the authors and do not necessarily reflect the views of the U.S. Agency for International Development.

Published in September 2002.

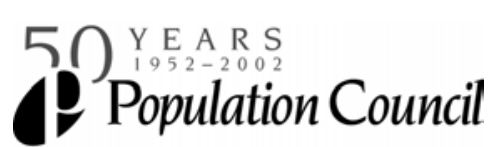

The Population Council is an international, nonprofit, nongovernmental institution that seeks to improve the wellbeing and reproductive health of current and future generations around the world and to help achieve a humane, equitable, and sustainable balance between people and resources. The Council conducts biomedical, social science, and public health research and helps build research capacities in developing countries. Established in 1952, the Council is governed by an international board of trustees. Its New York headquarters supports a global network of regional and country offices. 


\section{Table of Contents}

Executive Summary

Introduction 4

Methodology 6

Orientation and initial contact $\quad 6$

$\begin{array}{ll}\text { Ethnography } & 6\end{array}$

$\begin{array}{ll}\text { Survey } & 7\end{array}$

Group discussions

$\begin{array}{ll}\text { Ethical issues } & 8\end{array}$

$\begin{array}{ll}\text { Limitations of the study } & 8\end{array}$

Findings 9

Identities and social roles $\quad 9$

First sexual experience and subsequent relationships $\quad 11$

$\begin{array}{lr}\text { Stigma, violence, and rejection } & 12\end{array}$

HIV/STI vulnerability 13

$\begin{array}{ll}\text { Health-seeking behavior } & 15\end{array}$

Conclusions and Next Steps 17

$\begin{array}{lr}\text { References } & 18\end{array}$ 



\section{Executive Summary}

Research conducted in many countries has highlighted the vulnerability of men who have sex with men (MSM) to HIV and other sexually transmitted infections (STIs). Yet in Africa, they receive little attention in HIV/AIDS programming and service delivery because of widespread denial and stigmatization of homosexual behavior. In Dakar, Senegal, a study conducted by researchers from the National AIDS Control Council (CNLS), Cheikh Anta Diop University, and the Horizons Program used ethnographic and survey methods to elicit information about the needs, behaviors, knowledge, and attitudes of MSM. In the ethnographic phase, the researchers conducted group discussions and interviews with MSM and people who interact with them, such as bartenders, female sex workers, and taxi drivers. In the second phase, the researchers surveyed a convenience sample of $250 \mathrm{MSM}$, ranging in age from 18 to 53 years.

The research team recruited informants by visiting areas frequented by MSM and by making contact and building trust with MSM and MSM leaders. As part of the research process, the research team spent a lot of time examining their own preconceived notions about sexuality, working through prejudices and taboos, and stressing the importance of maintaining the confidentiality of informants. All interviews were anonymous and informants were asked to provide oral informed consent. Upon consent, informants received a small stipend (2,500 F CFA) to cover travel costs, information on STIs and HIV/AIDS, and a referral for a free medical consultation and treatment.

\section{Key Findings}

MSM have distinct identities and social roles that go beyond sexual practices. Broadly defined, Ibbis are more likely to adopt feminine mannerisms and be less dominant in sexual interactions. While society may formally reject homosexuality, this does not prevent Ibbis from occupying positions of high regard in certain circles. For example, Ibbis often have close relationships with women who have political or economic power, for whom they carry out important social ceremonies and functions. In several neighborhoods, Ibbis enjoy the protection of the entire community. Yoos are generally the insertive partner during sex and do not consider themselves to be homosexuals. Beyond these broad categories, there are additional subcategories based on age, status, and type of relationship. However, identification with a particular group is not a good predictor of an individual's sexual practices.

The first sexual experience often occurs with an adult during adolescence. Survey respondents' first sexual encounter with a man occurred on average at 15 years. This experience was often with an adult, someone they knew or had recently met. A third of the sample reported that the adult was part of the respondent's extended family.

Sex with men is driven by many reasons, including love, pleasure, and economic exchange. Many of the men's histories highlight that their initial and subsequent sexual experiences occurred in the context of emotional and physical attraction. Economic exchange also plays a significant role. Two-thirds of the survey sample reported that they received money as part of their most recent 


\section{Hgrizons}

sexual encounter, and 9 percent had given money in exchange for sex. MSM reported a wide range of sexual relationships, including a regular stable relationship with a single partner, a regular relationship with one partner plus occasional partners, and irregular relationships with many partners. The vast majority of MSM have had sex with women. Eighty-eight percent of the survey sample reported ever having vaginal sex, and nearly a fifth had had anal sex with a woman.

The lives of many MSM are characterized by violence and rejection. Forty-three percent of MSM had been raped at least once outside the family home and 37 percent said they had been forced to have sex in the last 12 months. Thirteen percent reported being raped by a policeman. Nearly half of the 250 men interviewed had experienced verbal abuse (including insults and threats) from their family. Many also reported physical abuse (e.g., blows, stone throwing) by family and community members and the police. The study found a good deal of mobility among the men, both voluntary and involuntary; nearly a fourth reported being forced to move in the last 12 months. Numerous MSM emphasized the importance of keeping one's sexual inclinations and relationships a secret because exposure leads to ostracism, stigmatization, and physical or verbal abuse.

Many MSM are at high risk of HIV because of unprotected sex, a history of STI symptoms, and poor knowledge of STIs. When asked about condom use at last sex, only 23 percent of those reporting insertive anal sex said they used a condom. The figure for receptive anal sex was much lower: 14 percent. Condom use with women was also low: 37 percent said they used a condom the last time they had sex with a woman.

Informants identified a number of obstacles to condom use, including reduced pleasure, interference with establishing trust, and a lack of power on the part of some MSM to request condoms. According to one informant, "If a Yoos doesn't want to use a condom, there's not much an Ibbi can say." Informants also mentioned the high cost of preferred condom brands and poor access to water-based lubricants. Almost all of the MSM surveyed knew that HIV/AIDS could be contracted through sexual intercourse and 80 percent cited condoms as a way to prevent the disease, although actual use does not reflect knowledge.

Many respondents reported having experienced STI-related symptoms. For example, 42 percent had had burning or penile discharge and 22 percent reported having had lesions or pustules on their anus. When asked about the causes of penile discharge or burning, most respondents mentioned such non-viral or bacterial causes as poor hygiene, irritation from intercourse without sufficient lubrication, spicy foods, long periods of abstinence, masturbation, too much sex, or other illnesses. More than a third said they had no idea of the cause.

Health-seeking behavior for STI symptoms frequently involves delay and concealment. MSM noted that they are particularly resistant to the idea of revealing anal symptoms at clinics and hospitals because they risk exposing their homosexuality. Some men noted that health center staff had treated them with scorn or ignored them completely, and did not respect their confidentiality. Hence some informants spoke of doing nothing to treat their symptoms or self-medicating with medicine purchased without a prescription. However, because there is less stigma associated with penile symptoms, such as discharge, burning, itching, and sores, MSM are more likely to visit a 
public hospital or clinic for treatment of these conditions. When asked where they would prefer to go for treatment of anal and penile symptoms, the majority mentioned public hospitals and dispensaries, provided that they remain affordable and treat clients with confidentiality and respect.

\section{Conclusions and Next Steps}

This study provides important insights about the sexuality of MSM, their risk of HIV/STIs, and the role of violence and stigma in their lives. The findings also highlight the lack of sexual health services and information available to meet their particular needs.

The findings from this study were disseminated at a meeting held in April 2001 in Dakar and have catalyzed awareness of the public health importance of developing non-stigmatizing interventions for MSM. As a result, a task force of NGOs and the USAID Mission, under the auspices of the CNLS, has been formed to develop and coordinate services for MSM in Dakar. Potential intervention components include behavior change communication, capacity building of MSM leaders, training of peer educators, sensitizing service providers to the health needs of MSM, creation of spaces that are safe and comfortable where MSM can gather to exchange information, and liaising with police to reduce violence against MSM. 


\section{Hgrizons}

\section{Introduction}

Although sex between men occurs in most societies (Herdt 1997), its existence and importance for HIV/AIDS prevention are frequently overlooked in the developing world (UNAIDS 1998). Denial of sexual behavior between men, stigmatization or criminalization of MSM, difficulty in reaching MSM, inadequate epidemiological information on HIV transmission through male-to-male sex, inappropriate or inadequate health services, and the lack of donor funding are critical barriers to research and service delivery (UNAIDS 2000a).

Despite widespread ostracism, denial, and rejection, MSM in the West have played key roles in successful social mobilization efforts to prevent the spread of HIV/AIDS (Foreman 1998). Within the African context, however, the question of the existence of MSM generally meets with severe hostility (McKenna 1996). Compared to other regions of the world, Africa has the lowest level of public awareness and discussion of MSM, and 55 percent of African countries have laws against men having sex with men (McKenna 1996). The phenomenon of MSM is considered extremely marginal, closely associated with European or Western contamination, and there is a deep belief that it has no roots in traditional African society (McKenna 1996; Panos Institute 1991).

In Africa, very few social and behavioral studies exist on MSM. In the anthropological literature, there are several references to the existence of male homosexuality in different parts of Africa (Tauxier 1912; Evans-Pritchard 1929; Werner 1987). In Senegal, Crowder (1959) described its existence in Wolof society and concluded that the phenomenon is well entrenched within this society. There has been some documentation of men having sex with men in prisons in Africa with the aim of developing strategies to prevent HIV/AIDS in that context. For example in a study conducted by Simooya et al. (2001) in Zambia, 8.4 percent of prisoners reported homosexual intercourse, although indirect questioning imply a much higher figure. Interviews with prisoners in Nigeria suggest the existence of widespread male-to-male intercourse (Orubuloye, Omoniyi, and Shokunbi 1995). But beyond research conducted with prison populations, there has been little work by African researchers on the identity and behavior of MSM with the goal of developing HIV prevention and care programs that meet the needs of MSM.

In Senegal there has been some investigation of MSM in the community context. Teunis (1996) conducted an ethnographic study of MSM in Dakar, which describes how cultural and economic forces shape their sexual and social relationships. Many of Teunis' findings on the nature of relationships among MSM were corroborated by researchers from the University Cheikh Anta Diop as part of a study they conducted on migration and HIV/AIDS in Senegal (UNAIDS 2000b). The research team conducted focus groups, in-depth interviews, and obtained life histories from men recruited at bars, restaurants, and dance halls frequented by migrant and mobile populations. Although the researchers did not set out to specifically investigate MSM, the study provided important data about the sexual sub-cultures of MSM, their language and types of relationships, and the social and economic environment of MSM in Senegalese society. 
This study builds on these earlier findings in order to better understand the lives of MSM in Senegal so that appropriate STI/HIV interventions can be developed to meet their needs. Because previous research indicates that many MSM also have sex with women, protecting MSM from HIV/AIDS has wider implications for the health of families and communities (Foreman 1998). 


\section{Hgrizons}

\section{Methodology}

The study was a collaboration between researchers from the PNLA, Cheikh Anta Diop University, and the Horizons Program. The aims of the study were to increase understanding about the sexuality of MSM; identify the social, cultural, behavioral, and service delivery factors that place MSM at risk for contracting STIs, including HIV/AIDS; and use this information to sensitize policymakers and program managers to the need for non-stigmatizing interventions for this population.

The researchers used ethnographic and survey methods to elicit information from MSM, 18 years of age or older, from several neighborhoods in Dakar. The study consisted of four phases: (1) orientation to the study sites and initial contact, (2) ethnographic data collection through observation, informal and semi-structured interviews, and case histories, (3) survey administration, and (4) group discussions.

\section{Orientation and Initial Contact}

During the first phase, the researchers visited bars, cafeterias, restaurants, and public places believed to be frequented by MSM. Researchers first made contact with people who interact socially with MSM ("gatekeepers"). It took several meetings between the researchers and these individuals for the latter to understand the objectives of the research and its confidentiality safeguards. This phase was crucial for putting informants at ease in order to elicit information on where MSM meet and to facilitate introductions to MSM and others who interact with them. Sometimes the researchers faced reticence and resistance when introduced to a potential informant, and only proceeded if the subject was willing to do so and provided informed consent. Thus, the MSM who agreed to participate in the research represent only a portion of the individuals who were initially contacted.

\section{Ethnography}

In the second phase, the researchers conducted observation at 19 sites where MSM meet and interact. The researchers also carried out 23 unstructured individual interviews with individuals who are in close proximity to MSM (e.g., bartenders, female sex workers, waiters, taxi drivers, female models); with those who occupy positions of elder mentor, leader, or celebrity within the MSM community; and with directors of programs or NGOs involved in combating AIDS.

Also as part of the ethnographic phase, the researchers conducted semi-structured interviews with 18 MSM and detailed case histories of eight other MSM in order to learn more about their sexual initiation; family, social and sexual relationships; drug and alcohol use; and sexual health problems. 


\section{Survey}

In the third phase, the researchers administered a survey to a convenience sample of $250 \mathrm{MSM}$. The survey elicited the following types of information from respondents:

- Sociodemographic characteristics.

- Problems encountered in the immediate and extended family, and in the community.

- STI knowledge, symptoms, treatment experiences, and preferred sources of information and treatment.

- HIV/AIDS knowledge, attitudes, and preventive behaviors.

- Attitudes toward people living with HIV/AIDS.

- Sexual behavior with men and women.

- Condom use.

The researchers interviewed a sample of $250 \mathrm{MSM}$ using a structured survey instrument. To be included in the survey, the respondent had to be 18 years or older and acknowledge ever having had intimate sexual relations with a man. The researchers recruited subjects using snowball sampling, which consisted of working with recognized leaders to recruit other MSM, who then helped to recruit others until 250 men had been interviewed. Given that the questionnaires were anonymous, the researchers attempted to put control measures into place to avoid cases of duplication. For example, the MSM leaders were asked to stress to potential respondents the importance of being interviewed only once.

Survey respondents ranged in age from 18 to 53 years, with a mean age of 25 years. Eighty-two percent were single and 15 percent reported being married; some were in polygamous marriages. About a fourth of the men had children. More than a third of the sample were Wolof, with many other ethnic groups represented, including Toucouleur, Lébou, and Peul. The level of education is relatively low: 15 percent had never been to school and 55 percent had not completed elementary school. Respondents reported a range of income levels (low, middle, and high) and occupations, including professional athletes, mechanics, artists, laborers, merchants, Muslim marabous, and students. Twenty-four percent were unemployed.

\section{Group Discussions}

In the last phase the researchers conducted discussions with six groups of MSM to gather information about sexual behavior and community attitudes toward MSM. Each group consisted of six to ten participants. Older MSM who did not want to respond to the questionnaire made up one of the groups. Other aims of the discussion groups were to obtain feedback on the data previously collected and discuss the feasibility of intervention strategies that were emerging from the research. 


\section{Hgrizons}

\section{Ethical Issues}

As part of the research process, the research team spent a lot of time examining their own preconceived notions about sexuality, working through prejudices and taboos, and stressing the importance of maintaining the confidentiality of informants. All interviews were anonymous, and informants were asked to provide oral informed consent. Upon consent, informants received a small stipend (2,500 F CFA) to cover travel costs, information on STIs and HIV/AIDS, and a referral for a free medical consultation and treatment. The interviewers always asked about preferred sites for data collection. In some cases the researchers conducted interviews in cars or where MSM live or spend time. Other times the interviews were conducted in an office at the university.

\section{Limitations of the Study}

Our study contains a number of limitations related to the respondents and the topics addressed. First, snowball sampling was used to recruit informants. Although the technique was successful in recruiting $250 \mathrm{MSM}$, it nevertheless resulted in a selection bias. For example, 83 percent of survey respondents were under 30 years of age. This may be due to the fact that all of the interviewers were young people and that older MSM were reluctant to talk with someone their junior, especially about such a stigmatized topic. Therefore we acknowledge that the sample is not representative of MSM in Dakar.

Second, the study focused on the experiences and perspectives of MSM in order to develop interventions that respond to their needs. However, we did not interview some groups who would be critical for intervention design and implementation, such as health care workers and policemen.

Finally, we note that a number of key HIV-related topics were not addressed in the interviews, such as experiences with condom breakage, non-penetrative sex, HIV testing, and lubricants. 


\section{Findings}

\section{Identities and Social Roles}

In Wolof society, the most frequently used term for MSM is gor jigeen, which is translated literally in English as "man-woman." It implies a man who is very close to the world of women, to the point of identifying with them. Gor jigeen is currently considered discriminatory and demeaning by MSM. As one MSM stated, "The term Gor jigeen frightens us. When someone says it in our presence, it makes us shiver. The term is like a siren sound that we expect to be followed by insults, blows, or stones thrown at us by out-of-control mobs."

Among MSM, they prefer the terms Ibbi and Yoos. Broadly defined, Ibbis are more likely to adopt feminine mannerisms and be less dominant in sexual interactions. While society may formally reject homosexuality, this does not prevent Ibbis from occupying positions of high regard in certain circles. For example, Ibbis often have close relationships with women who have political or economic power for whom they carry out important social ceremonies and functions. In several neighborhoods, Ibbis enjoy the protection of the entire community. Yoos are generally the insertive partner during sex and do not consider themselves to be homosexuals.

Beyond these broad categories, there are additional subcategories based on age, status, and type of relationship. According to an informant from Médina, "Boys' men are young Ibbi; they are effeminate [outwardly] and feminine in spirit, whereas the Gentlemen are young Yoos." Gentlemen are described as "tough" or "macho" and are heavily involved in alcohol and drug networks. The social construct of the Yoos-Ibbi relationship is generally unequal in nature, revolving around the dominator/dominated, masculine/feminine dichotomy. In ceremonies, the Yoos are served food by the Ibbi. Moreover, the Yoos eat with spoons, while the Ibbi (like women) eat with their hands.

The categories Ibbi and Yoos have more to do with identity and status than with sexual practices. For example, an MSM may call himself an Ibbi or be considered as such in the community, but he may also have a sexual relationship with another $I b b i$ and they both may practice insertive and receptive anal intercourse. Therefore, identification with a particular group is not a good predictor of an individual's sexual practices, as illustrated by one MSM, a fisherman by profession:

There are a lot of homosexual relationships among fishermen when they are at sea. In my case, I was exclusively Yoos at the beginning, until one day, out of curiosity, I wanted to know what it felt like to be an Ibbi, so I had a passive sexual encounter, and ever since, I can't do without it. But I do it on the sly, and my regular partners still think of me as a Yoos. 


\section{Hgrizons}

$I b b i$ are often bound together by networks of intense relationships. Within their community, they develop a system of communication by code to protect the secret of their sexual orientation. One of them declared,

When two Ibbi meet in a car or a bus, they easily recognize each other right from the start. The clothes they wear can be an external sign of belonging to the Ibbi family. Some Ibbi may wear women's clothes, but that is not the case for most Ibbi. Their way of dressing is not enough to identify the Ibbi. You know many individuals who wear a large boubou on Friday to go to Muslim prayer; well, the Ibbi, if he wants, can wear the same boubou, have the same masculine mannerisms, and identify completely with the faithful on the way to prayer. But from the moment he wants to communicate with another Ibbi with him in the mosque, he has a way of moving the sleeve of his boubou, of undulating his hips, of rolling his eyes, that identifies him exclusively to the one who belongs to his community of sexual preference.

A young MSM said along the same lines, "You recognize a boys' man by his gaze, sometimes it's the way he cinches his belt, or the buttons on his shirt that he doesn't close, or again, certain marks on his clothing that give him away."

Informants highlighted the importance of secrecy: hiding your inclinations, your relationships, and your sexual practices. According to one MSM, "When you meet some of the older Ibbi, they will give you the surname that you are to call them by. You never call them by their real name. They will do whatever it takes to keep you from learning their real name."

While the society at large may adopt attitudes of formal rejection toward homosexuality that may even find expression in violence, this does not prevent the Ibbi from occupying positions of high regard in certain segments of society. For example, some Ibbis have close relationships of trust and confidence with women who are thought to have a great deal of political, economic, or social power. The Ibbi perform specific tasks and functions for these ladies: They give them advice on clothes and make-up, cook for certain special occasions, and help organize marriage and baptism ceremonies or social gatherings. One MSM explained to us that during the years from 1950 to 1960, each "great lady" affiliated with one of the competing political parties had around her a group of MSM who acted as her publicists (advertising her virtues), hurling vitriolic verbal attacks at the great lady's women rivals. In return, the ladies provided the MSM with material and financial support.

In addition to these ladies, traditionally called "Gor jigeen mothers," an Ibbi might establish a special relationship with a young woman, whom he then calls his "sister" (jigeen). He would see to her appearance, preparing henna or make-up for her and doing her hair. He would be this young woman's confidant, in a relationship of friendship and mutual respect without any possibility of having sexual relations. The young woman, in return, would call him "Camen."

In several traditional Lébou neighborhoods, we observed that the Ibbi enjoy the protection of the entire community. One informant stated concerning this, "No one dares insult an Ibbi who is a member of our community; he is protected the way you would protect the insane. If you hear that someone has thrown stones at one of them, you can be sure that person was not from this neighborhood." 


\section{First Sexual Experience and Subsequent Relationships}

The first sexual experience with a man often occurs during adolescence with an adult they know or have recently met. Survey respondents' first sexual encounter occurred on average at 15 years (range: 7 to 31 years). A third of the survey sample reported that the adult was part of the respondent's extended family. According to one study informant :

We were seven boys in Kolda. Our mother waited a long time to have a daughter. And I was the youngest. My mother made me wear girl's clothes. Also, I slept in the same room with my uncle due to the lack of space in the house. I was 12 years old and he was much older. One night, he took off my shorts, touched me on the behind and penetrated me. In the morning, he left and didn't come back for a month.

Another informant told about the influence of a man known to the family:

One day, an adult man, an important gentleman who frequented the house, invited me to his house. When I arrived, he asked me to give him a massage. I bowed to his wishes, and he began to relax. I was afraid, because I didn't understand where he was going. Then he took my hand and placed it on his sex. I let him do it. He also caressed my sex. Afterwards, he gave me 400 F CFA to cover my transportation. That shocked me. Nevertheless, he invited me back again and I accepted the invitation. That time, everything went too fast; he penetrated me and we had sexual relations.

In some cases, the relationship with an adult was preceded by sexual play with other boys. As one MSM recounted:

At home, I took baths with my friends and my cousins, and we amused ourselves trying to penetrate each other with soap. At the age of ten, I went to the beach with some friends, and I met a gentleman who approached me under the pretext that I looked a lot like his nephew. He promised to show me his nephew so that I could see our resemblance for myself. One day, as I was leaving school, I saw him. We spoke. He suggested that I come to his house. He gave me $1,000 \mathrm{~F}$ CFA for the taxi. The day came and I went to his house. I expected to see his nephew. After long discussions over soft drinks and cake, he admitted to me that he had no nephew and that he lived alone. He told me he wanted to make love to me; I was afraid and I told him so. He told me I just had to try it. One thing led to another, and as he caressed me, I remembered that I had done that with my cousins and my friends. But with him, I went much further.

Some of the men's histories highlight that their initial and subsequent sexual experiences occurred in the context of emotional and physical attraction.

In 1993, I got my diploma and moved along with my family. I met a man who asked me to accompany him to a party of other men. I was curious about his milieu, and I went. Another day, I came home at 11 p.m. with him. He introduced me to his friends. He came on to me and 


\section{Hgrizons}

caressed me a lot. I felt a tremendous amount of pleasure. We went to his house and he penetrated me. I felt happy and proceeded to have a very strong love relationship with him.

In other cases, financial need was a main motivation for first engaging in sex with a man. As a young Wolof man recalled:

He invited me to his house the following day. He gave me money. I kept my date with him. We were alone. The atmosphere was hushed. Around 2 a.m., he asked me to lie down on the couch. He went to take a shower, and came back in a bathrobe, and we began to caress each other. When it came time for me to leave, he again offered me a lot of money, really a lot. And he asked me to come back as often as I liked, which I accepted. In the end, we had sexual relations with penetration. And I acquired a taste for the pleasure and for the money. He took care of all my debts. For my part, I made myself available to him every Saturday.

Economic exchange plays an important part in the current sexual experiences of the men in our study as well. Two-thirds of the survey sample reported that they received money as part of their most recent sexual encounter with another male, and 9 percent had given money in exchange for sex.

Given that sex among men is driven by many reasons - love, pleasure, and economic gain — it is not surprising that MSM reported a wide range of relationships, including a regular stable relationship with a single partner, a regular relationship with one partner plus occasional partners, and irregular relationships with many partners. The vast majority of MSM have also had sexual relationships with women. Eighty-eight percent of the survey sample reported ever having vaginal sex, and nearly a fifth had had anal sex with a woman. Some of these sexual encounters involved an exchange of money: 21 percent of MSM reported giving money at the time of their last sexual encounter with a woman and 13 percent said they received money.

\section{Stigma, Violence, and Rejection}

The lives of many MSM are characterized by violence and rejection. Forty-three percent of the MSM surveyed had been raped at least once outside the family home, and 37 percent said they had been forced to have sex in the last 12 months. Thirteen percent reported being raped by a policeman. Nearly half of the 250 men interviewed had experienced verbal abuse (including insults and threats) from their family and 19 percent at a police station (Table 1). As one informant noted, "The most humiliating thing was when the police officer told my mother, who had come to see me while I was being detained: 'You didn't bring a male child into the world; your son is a homosexual."” 
Table 1 Percent of MSM experiencing abuse $(n=250)$

Source or Setting of Abuse

Family

49

28
Community

40

12
Police Station

19

13

Many also reported physical abuse (e.g., blows, stone throwing) by family and community members and the police. The study found a good deal of mobility among the men, both voluntary and involuntary; nearly a fourth reported being forced to move in the last 12 months. Numerous MSM emphasized the importance of keeping one's sexual inclinations and relationships a secret because exposure leads to ostracism, stigmatization, and physical or verbal abuse. According to one informant:

In certain neighborhoods, when they find out you are an Ibbi, you may be just passing through, but the young people will get together and start throwing stones at you....You have the impression then that it's raining stones.

Religious reasons are the ones most frequently invoked to justify rejection of the MSM. A Muslim dignitary explained, "Since the Muslim religion forbids homosexuality, we cannot accept homosexuals either in our homes or in our mosques." Another cleric explained that when a Muslim shakes hands with a homosexual, a certain number of prayers are required for his purification. MSM often invoke religious reasons to affirm that their homosexual life is only for a limited period of time; they say that they expect to renounce it some day when they have grown old in order to bring themselves in line with the Muslim religion.

\section{HIV/STI Vulnerability}

Many survey respondents reported having experienced symptoms of STIs. For example, 42 percent had had burning or penile discharge, and 22 percent reported having had lesions or pustules on the anus (Table 2). When asked about the causes of penile discharge or burning, most respondents mentioned such non-viral or bacterial causes as poor hygiene, irritation from intercourse without sufficient lubrication, spicy foods, long periods of abstinence, masturbation, too much sex, or other illnesses. More than a third said they had no idea of the cause. 


\section{Hgrizons}

Table 2 History of STI symptoms $(n=250)$

\section{Symptom}

Discharge and burning in the penis

Bleeding and discharge from the anus

Swollen ganglia in the groin area

Itching and sores around the penis

Sores and pimples around the anus

Painful and swollen testicles
Percent who experienced symptom

42

42

36

24

22

12

In contrast to limited knowledge about STI symptoms, almost all of the 250 MSM knew that HIV/AIDS could be contracted through sexual intercourse and 80 percent cited condoms as a way to prevent the disease (Table 3), although actual use does not reflect knowledge.

Table 3 Knowledge of ways to prevent HIVIAIDS ( $n=250$ )

Means of prevention Percent

Condoms 80

Avoiding dirty objects 24

Choosing your partners well 15

Having a single partner 13

Other

Prayer or God's protection

Not having sex

Avoiding giving blood

Don't know

Avoiding blood transfusions

Note: Respondents could give more than one response. 
When asked about condom use at last sex, only 23 percent of the survey sample that reported insertive anal sex said they used a condom. The figure for receptive anal sex was much lower: 14 percent. Condom use with women was also low: 37 percent said they used a condom the last time they had sex with a woman. Informants identified a number of obstacles to condom use, including reduced pleasure, interference with establishing trust, and a lack of power by some MSM to request condoms. According to one informant, "If a Yoos doesn't want to use a condom, there's not much an Ibbi can say." Informants also mentioned the high cost of preferred condom brands and poor access to water-based lubricants. Availability of condoms does not seem to be a barrier: 86 percent of MSM thought condoms were easy to find.

\section{Health-seeking Behavior}

Health-seeking behavior for STI symptoms frequently involves delay and concealment. MSM noted that they are particularly resistant to the idea of revealing anal symptoms at clinics and hospitals because they risk exposing their homosexuality, whereas symptoms on the penis, even if they revealed certain "shameful diseases," do not in themselves reveal their homosexuality. Homosexuality is considered to be less well tolerated than such "shameful diseases." Some men noted that health center staff had treated them with scorn or ignored them completely, and did not respect their confidentiality.

Hence some informants spoke of doing nothing to treat their symptoms or self-medicating with medicine purchased without a prescription. However, because there is less stigma associated with penile symptoms, such as discharge, burning, itching, and sores, MSM are more likely to visit a public hospital or clinic for treatment of these conditions.

When asked where they would prefer to go for treatment of anal and penile symptoms, the majority mentioned public hospitals and dispensaries, provided that they remain affordable and treat clients with confidentiality and respect. Most MSM believe that doctors are the most reliable source of information on STIs, which is why they would prefer to seek information and care from the formal health system. Healers and marabous were rarely cited as preferred sources of treatment. There also was little support for a special facility because they said it would risk reinforcing their ostracism. Similarly, the most preferred source of information on HIV/AIDS is the health center, even though radio and television have been the most common sources of information on the topic (Table 4). 


\section{Hgrizons}

Table 4 Current and preferred sources of information about HIVIAIDS ( $n=250$ )

\section{Current source of} information (\%)

Preferred source of information (\%)

\begin{tabular}{llr}
\hline Radio & 54 & 25 \\
Television & 50 & 20 \\
Friends & 22 & 19 \\
Lectures/small group talks & 17 & 19 \\
Other & 16 & 11 \\
Newspapers & 13 & 6 \\
Health centers & 12 & 31 \\
Partners & 2 & 3 \\
Note: Respondents could give more than one response. & &
\end{tabular}

25

20

19

19

11

6

31

3 


\section{Conclusions and Next Steps}

This study provides important insights about the sexuality of MSM, their risk of HIV/STIs, and the role of violence and stigma in their lives. The findings also highlight the lack of sexual health services and information available to meet their particular needs.

Research conducted among MSM in Madagascar revealed similar vulnerabilities (Célestine 1998). Respondents in this study identified a number of strategies for meeting the needs of MSM for prevention and care, including training peer educators, holding community workshops, making condoms available in places frequented by MSM, and reducing the stigmatization and discrimination among health professionals through sensitivity training. A recent meta analysis of nine controlled studies evaluating the effects of interventions for MSM in the United States concluded that community-level interventions and small group efforts can substantially reduce sexual risk in this population (Johnson et al. 2002). Given our findings, such intervention strategies are applicable to the Senegalese context as well.

The findings from this study were disseminated at a meeting held in April 2001 in Dakar and have catalyzed awareness of the public health importance of developing non-stigmatizing interventions for MSM. As a result, a task force of NGOs and the USAID Mission, under the auspices of the CNLS, has been formed to develop and coordinate services for MSM in Dakar. Potential intervention components include behavior change communication, capacity building of MSM leaders, training of peer educators, sensitizing service providers to the health needs of MSM, creation of spaces that are safe and comfortable where MSM can gather to exchange information, and liaising with police to reduce violence against MSM. 


\section{Hgrizons}

\section{References}

Célestine, R. 1998. Etude du Comportement des Hommes Ayant des Relations Sexuelles avec d'autres Hommes en Matière de Prévention des MST/SIDA à Antananarivo, Madagascar. Unpublished medical thesis.

Crowder, M. 1959. Pagans and Politicians. London: Hutchinson.

Diop, A.B. 1981. La société Wolof- Les systèmes d'inégalité et de domination ("Wolof Society: Systems of Inequality and Domination”). Editions Karthala. Paris: IFAN, René Descartes.

Evans-Pritchard, E.E. 1929. Witchcraft (Mangu) among the A-Zande. Sudan Notes and Records XII: 163-249. Khartoum: McCorquodale.

Foreman, M., editor. 1998. AIDS and Men: Taking Risks or Taking Responsibility. London: Panos Institute.

Herdt, G. 1997. Same Sex, Different Cultures. Boulder: Westview Press.

Johnson, W.D. et al. 2002. "HIV Prevention research for men who have sex with men: A systematic review and meta-analysis." Journal of Acquired Immune Deficiency Syndrome 30: S118-S129.

McKenna, N. 1996. On the Margins: Men Who Have Sex With Men and HIV in the Developing World. London: Panos Institute.

Orubuloye, I.O., O.P. Omoniyi, and W.A. Shokunbi. 1995. "Sexual networking, STDs and HIV/AIDS in four urban gaols in Nigeria." Health Transition Review, Supplement to Vol. 5: 123130.

Panos Institute. 1991. "Unsung heroes in the south." WorldAIDS (Nov.): 5-8.

Simooya, O.O. et al. 2001. " 'Behind walls': a study of HIV risk behaviors and seroprevalence in prisons in Zambia," AIDS 15(13): 1741-1744.

Tauxier, L. 1912. Le noir du soudan, pays Mossi et Gourounsi : Documents et Analyses ("The Blacks of Sudan: Mossi and Gourounsi Country, Documents and Analysis"). Paris: Emile Larose, Librairie - Editeur.

Teunis, N. 1996. "Homosexuality in Dakar: Is the Bed the Heart of Sexual Subculture?" Journal of Gay, Lesbian and Bisexual Identity 1(2): 153-169.

UNAIDS. 1998. "AIDS and Men who Have Sex with Men." Best Practices: Point of View. Geneva: UNAIDS. 
UNAIDS. 2000a. “AIDS and Men who Have Sex with Men.” Best Practices: Technical Update. Geneva: UNAIDS.

UNAIDS. 2000b. Résultats de recherche - action, Projet Migration et SIDA, IOA/ONUSIDA. ("Action Research Results, Migration and AIDS Project"). Abijan: UNAIDS Inter-Country Team for West and Central Africa.

Werner, D. 1987. Human Sexuality Around the World. Unpublished manuscript of the Human Relations Area Files. www.yale.edu/hraf. 


\section{$\mathrm{H}$ rizons}

Horizons is a global operations research program designed to:

Identify and test potential strategies to improve HIV/AIDS prevention, care, and support programs and service delivery.

-Disseminate best practices and utilize findings with a view toward scaling up successful interventions.

For more information, please contact:

Horizons Program, Communications Unit 4301 Connecticut Avenue, NW Suite 280 Washington, DC 20008 USA

Tel: 202-237-9400

Fax: 202-237-8410

Email: horizons@pcdc.org

www.popcouncil.org/horizons

\section{$5 \bigcap_{1952-2002}^{Y E A R S}$ QPopulation Council}

Horizons is implemented by the Population Council in collaboration with - International Center for Research on Women (ICRW)

- International HIV/AIDS Alliance

- Program for Appropriate Technology in Health (PATH)

- Tulane University

· Family Health International (FHI) · Johns Hopkins University 